\title{
Backside Protection for Wendelstein 7-X In-vessel Components
}

\author{
J. Zhu, V. Bykov, A. John, L. Wegener, H-S. Bosch and W7-X team
}

\begin{abstract}
Successful physical experiment campaigns have been performed on the most advanced modular stellarator Wendelstein 7-X (W7-X) during the second operation phase (OP1.2). The completion phase (CP2) lasting until 2021 is devoted to the installation of cryo-vacuum pumps (CVPs), new diagnostics and actively cooled in-vessel components instead of the inertially cooled ones used in OP1.2. This update allows to move forward to achieve the steady state operation during next operation phase (OP2). Several first wall components which are exposed to heat flux in the range from 250 to $500 \mathrm{~kW} / \mathrm{m}^{2}$ are covered by graphite tiles facing the plasma. Due to construction constraints, the backside area of the graphite tiles is not fully covered by the actively cooled CuCrZr heat sinks. That results in the presence of high temperature graphite rims, which become an additional heat radiation source for the components behind the first wall.

This paper presents stepwise development of backside protections (BSP) to mitigate the problem mentioned above. The process is supported by

1) study of BSP shielding performances through thermal analysis taking into account plasma radiation and ECRH loads;

2) BSP sizing restricted by electromagnetic forces during main coils / plasma current decay;

3) mechanical analysis to confirm structural fixation of BSP.

In addition, several analysis iterations for CVP have been repeated to minimize BSP cost by identification of first wall components with minor heat radiation to the CVP and marginal influence on its cooling system capacity.
\end{abstract}

Index Terms-Wendelstein 7-X (W7-X), stellarator, in-vessel components, backside protection, thermal analysis, electromagnetic forces, structural analysis.

\section{INTRODUCTION}

$\mathrm{S}_{\mathrm{p}}^{\mathrm{U}}$ UBSTANTIAL physical experiments have been successfully $\checkmark$ performed on the most advanced modular stellarator Wendelstein 7-X (W7-X) during the second operation phase (OP1.2) in 2017 and 2018. The completion phase CP2 is subsequently started, which is devoted to the installation of cryo-vacuum pumps (CVPs), new diagnostics and actively cooled in-vessel components instead of the inertially cooled ones used in OP1.2. The expected steady state operation (OP2) of W7-X is foreseen carrying out at 2021 with not only longer pulse but also higher plasma heating power [1], which increases

The authors are with the Max Planck Institute for Plasma Physics, EURATOM Association, Greifswald 17491, Germany (e-mail: jiawu.zhu@ipp.mpg.de (Corresponding author); victor.bykov@ipp.mpg.de; andre.john@ipp.mpg.de; lutz.wegener@ipp.mpg.de; bosch@ipp.mpg.de). the heat load on the first wall of in-vessel components in terms of convection, thermal radiation and the fraction of direct loads from heating system [2].

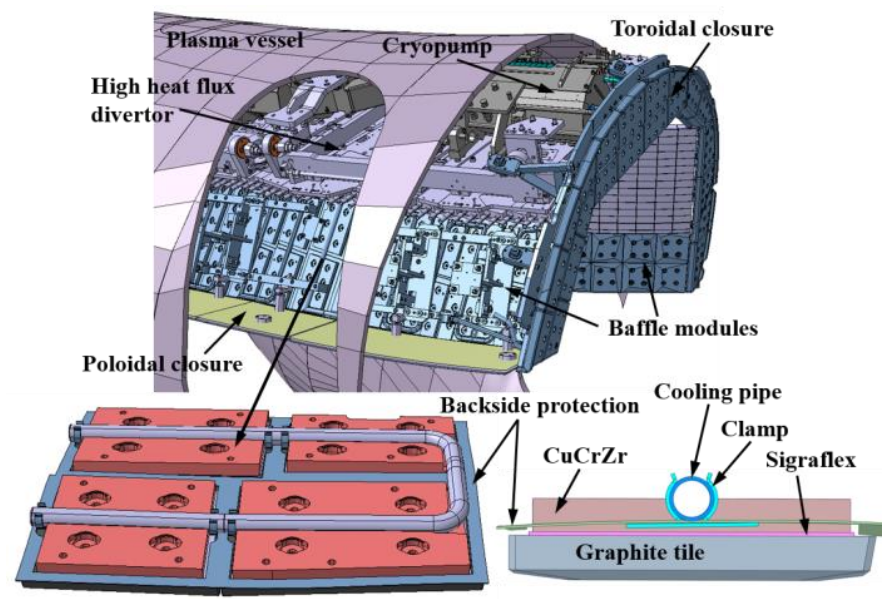

Fig. 1. View of some divertor components and the backside protection of Baffle modules.

The in-vessel components of W7-X could be classified into two major parts, i.e. divertor components and the wall protections. The divertor components consist of high heat flux (HHF) divertor, baffle modules (BM), divertor closures, cryo-vacuum pump (CVP) and control coils, each of them has ten similar discrete units situated in corresponding ten half modules of W7-X [3]. During steady state operation, the plasma facing wall of HHF and BM formed by graphite tiles will be exposed to the heat flux of up to $10 \mathrm{MW} / \mathrm{m}^{2}$ and 500 $\mathrm{kW} / \mathrm{m}^{2}$ respectively [3]. The backside area of $\mathrm{BM}$ is not fully covered by actively cooled $\mathrm{CuCrZr}$ heat sinks due to construction constraints, therefore the high temperature graphite rims become an additional heat radiation source for the components behind the BM, such as CVP, control coils, SS/Cu pipes, diagnostics, etc. Moreover, small fraction of plasma radiation and ECRH (electron-cyclotron resonance heating) stray radiation could penetrate the narrow gap $(\sim 1.3 \mathrm{~mm})$ between neighboring graphite tiles and further heat up the backside components. In order to mitigate the influences, the backside protection (BSP) is designed to reflect the heat radiation and intercept the ECRH stray radiation. Fig. 1 shows an example of BSP for some BM tiles. In general, the BSP comprises one / two layers of grids cut from $\mathrm{SS} / \mathrm{Cu}$ sheets that cooled by clamping on the cooling pipes and/or by radiation. The grid could be easily installed and removed on site when the bolted graphite tiles are demounted from the BM. 
At first, the paper presents the necessity to install the BSP and the target shielding effect in terms of the BM backside equivalent temperature for the most critical CVP in the divertor chamber of module 1 or 5 . The requirements are followed by the shielding effect study of BSP with respect to the number of grid layers, grids material and thermal contact conductance between the grids, clamps and cooling pipes. Secondly, the maximum electromagnetic (EM) forces in the BSP depending on grid sizes are estimated for the events of superconducting (sc) coils and plasma current decays. Finally, the structural stability of the BSP and its clamps under the maximum EM forces is assessed, and the maximum BSP grid sizes are proposed to withstand the EM forces. Moreover, in order to minimize the BSP costs, several thermal analysis iterations for the CVP are repeated to identifying the BM tiles with minor backside thermal radiation to the CVP and marginal influence on the CVP cooling system capacity [4].

\section{StUdy of BACKSIDE PROTECTION SHIELDING EFFECTS}

As shown in Fig.1, the BM (about 170 BMs in total) is a set of about 20 tiles, each tile consists of graphite tile, sigraflex (thermal insulation material), $\mathrm{CuCrZr}$ heat sink, and zigzag cooling pipe. During foreseen steady stead operation of W7-X, $\sim 1 / 5$ of the BM and TDA (toroidal closure) plasma facing area are exposed to $\sim 500 \mathrm{~kW} / \mathrm{m}^{2}$ plasma radiation, and the rest are exposed to $\sim 250 \mathrm{~kW} / \mathrm{m}^{2}$ [2], together with other effects, such as ECRH stray radiation, water cooling and thermal radiation, the equivalent temperature of BM / TDA backside surface could reach up to $\sim 600{ }^{\circ} \mathrm{C}$ in case of without BSP. According to the detailed thermal analysis of the CVP [4], the heat load on LN2 cooling circuit (one of the cooling circuits for CVP, protecting the helium panel from heat radiation) is quite sensitive to the backside temperature of neighboring in-vessel components due to the large temperature differences with them. Therefore, the BSP is necessary to be installed on the backside of BM and TDA to reflect the heat radiation from the hot graphite tile rims. The thermal analysis results of the CVP indicate that the LN2 cooling requirement could be fulfilled by the present cooling capacity in case the equivalent backside temperature of both the BM and the TDA is below $362{ }^{\circ} \mathrm{C}$. That value was taken as a goal for the design of the BSP.

\section{A. FE Model, Heat Loads and Boundary Conditions}

In order to study the shielding effect of the BSP, as shown in Fig. 2, a corner fragment of the BM module with several tiles are selected and modelled for FE thermal analysis. The specified heat loads and boundary conditions include:

1). Plasma radiation on plasma facing surfaces, $250 \mathrm{~kW} / \mathrm{m}^{2}$ or $500 \mathrm{~kW} / \mathrm{m}^{2}$,

2). ECRH stray radiation $38 \mathrm{~kW} / \mathrm{m}^{2}$ with absorption rate: $1 \%$ for $\mathrm{SS}$ and $0.2 \%$ for $\mathrm{Cu}$,

3 ). Thermal radiation between surfaces of graphite tile rims and the BSP with the assumed emissivity: 1.0 for graphite, 0.5 for both $\mathrm{SS}$ and $\mathrm{Cu}$,

4). Thermal radiation with surroundings is simulated by setting the ambient temperature to $150{ }^{\circ} \mathrm{C}$,

5). Partial plasma radiation passing through the gap between neighboring graphite tiles and shining on the BSP is set to 200 $\mathrm{W} / \mathrm{m}^{2}$

6). Water cooling convection coefficient of $30 \mathrm{~kW} / \mathrm{m}^{2} \cdot{ }^{\circ} \mathrm{C}$ (mass flow rate $470 \mathrm{~g} / \mathrm{s}$, inlet temperature $40{ }^{\circ} \mathrm{C}$ ) is assumed.

On top of these, as listed in Table I, several cases and options have been analyzed for comparison and optimization of the BSP:

- Number of BSP grid layers, i.e. one or two layers,

- BSP grids materials and thickness,

- Thermal contact conductance between the grids, clamps and cooling pipes,

- Transient behavior during maximum W7-X operation time period of 30 minutes.

The parameters of eight calculated cases are listed in Table I.

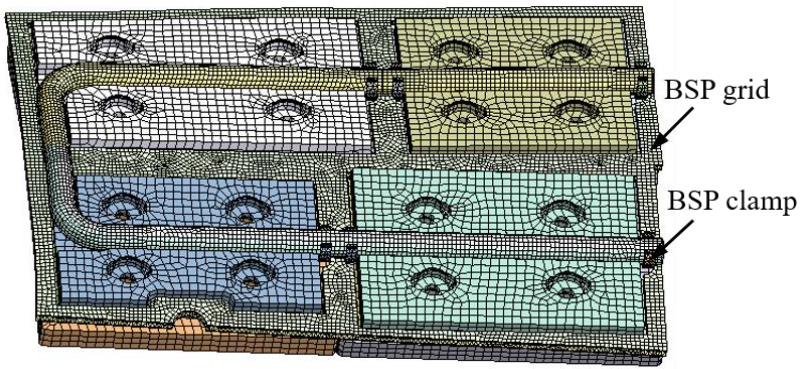

Fig. 2. FE model of some BM tiles with two layers BSP for shielding effects study.

TABLE I

CALCUlated CASES For STUdy OF BSP SHIELding EFFect

\begin{tabular}{|c|c|c|c|c|}
\hline Cases & $\begin{array}{c}\text { BSP grid } \\
\text { Layers }\end{array}$ & $\begin{array}{l}\text { BSP grid material } \\
\text { and thickness, mm }\end{array}$ & $\begin{array}{c}\text { Thermal contact } \\
\text { conductance }\end{array}$ & $\begin{array}{c}\begin{array}{c}\text { Analysis } \\
\text { type }\end{array} \\
\text {. }\end{array}$ \\
\hline${ }^{\mathrm{b}}$ Case 1 & None & I & I & Steady state \\
\hline Case 2 & One & ${ }^{\mathrm{c} S S} / \mathrm{Cu}(0.1 / 0.5)$ & Full contacted & Steady state \\
\hline Case 3 & Two & $\begin{array}{c}\mathrm{SS} / \mathrm{Cu}(0.1 / 0.5) \\
\text { and } \mathrm{Cu}(0.5)\end{array}$ & Full contacted & Steady state \\
\hline Case 4 & Two & $\begin{array}{c}\mathrm{SS} / \mathrm{Cu}(0.1 / 0.5) \\
\text { and } \mathrm{Cu}(0.5)\end{array}$ & $\begin{array}{l}\text { No contact } \\
\text { (floating) }\end{array}$ & Steady state \\
\hline Case 5 & Two & $\begin{array}{c}\mathrm{SS} / \mathrm{Cu}(0.1 / 0.5) \\
\text { and } \mathrm{Cu}(0.5)\end{array}$ & $20 \mathrm{~W} / \mathrm{m}^{2} \cdot{ }^{\circ} \mathrm{C}$ & Steady state \\
\hline Case 6 & Two & All with SS (0.5) & Full contacted & Steady state \\
\hline Case 7 & Two & All with SS (0.5) & $\begin{array}{l}\text { No contact } \\
\text { (floating) }\end{array}$ & Steady state \\
\hline Case 8 & Two & All with SS (0.5) & $\begin{array}{l}\text { No contact } \\
\text { (floating) }\end{array}$ & ${ }^{\mathrm{d}}$ Transient \\
\hline
\end{tabular}

a Thermal contacts between BSP grid, BSP clamp and cooling pipes.

${ }^{b}$ Without BSP. $\quad{ }^{\mathrm{c}}$ Composite material, SS facing plasma.

${ }^{\mathrm{d}}$ Start from room temperature state.

In addition, the thermal conductivities of SS/Cu $(0.1 / 0.5 \mathrm{~mm}$, taken from $\mathrm{Cu}$ ) and SS are listed in Table II [5-6].

TABLE II

THERMAL CONDUCTIVITY OF SS/Cu (0.1/0.5 MM) AND SS

\begin{tabular}{cccccc}
\hline \hline $\begin{array}{c}\text { Temp. }{ }^{\circ} \mathrm{C} \\
\mathrm{SS} / \mathrm{Cu},\end{array}$ & 27 & 100 & 200 & 361 & 500 \\
$\mathrm{~W} / \mathrm{m} \cdot{ }^{\circ} \mathrm{C}$ & 397 & 394 & 389 & 363 & 341 \\
$\begin{array}{c}\mathrm{SS}, \\
\mathrm{W} / \mathrm{m} \cdot{ }^{\circ} \mathrm{C}\end{array}$ & 15.3 & 15.64 & 16.95 & 18.51 & 18.51 \\
\hline \hline
\end{tabular}




\section{B. Analysis Results and Discussion}

For each case listed in Table I, two scenarios with heat flux of $250 \mathrm{~kW} / \mathrm{m}^{2}$ and $500 \mathrm{~kW} / \mathrm{m}^{2}$ respectively are analyzed separately, and the BM backside equivalent temperature of these two scenarios is calculated by summing up the thermal radiation flux of all backside elements using the following formula:

$A \cdot \varepsilon_{e q} \cdot \sigma \cdot T_{e q}^{4}=\sum_{i=e l e m} A_{i} \cdot \varepsilon_{i} \cdot \sigma \cdot T_{i}^{4}$

$A_{i}, \varepsilon_{i}$ and $T_{i}$ are the area, emissivity and temperature of each backside element. $\sigma$ is the Boltzmann constant. $A$ is the total backside area of the FE model. $\varepsilon_{e q}$ and $T_{e q}$ are the backside equivalent emissivity and temperature respectively. $\varepsilon_{e q}$ is assumed as 0.5 (the same of SS and $\mathrm{Cu}$ ). The overall backside equivalent temperature of the BM / TDA is then estimated according to the ratio of $1 / 5$ with $500 \mathrm{~kW} / \mathrm{m}^{2}$ and $4 / 5$ with 250 $\mathrm{kW} / \mathrm{m}^{2}$. Table III lists the overall backside equivalent temperature of all the cases, as well as the maximum temperature in $\mathrm{CuCrZr}$, BSP and Graphite tile for comparison. As an example, Fig. 3 shows the temperature distribution of Case 7 (with $250 \mathrm{~kW} / \mathrm{m}^{2}$ heat flux).

TABLE III

THERMAL ANALYSIS RESULTS OF ALL STUDIED CASES

\begin{tabular}{ccccc}
\hline Cases & $\begin{array}{c}\text { aTeq, }{ }^{\circ} \mathrm{C} \\
\text { Case 1 }\end{array}$ & $\begin{array}{c}\text { Max. Temp. in } \\
\mathrm{CuCrZr},{ }^{\circ} \mathrm{C}\end{array}$ & $\begin{array}{c}\text { Max. Temp. in } \\
\text { Graphite tile, }{ }^{\circ} \mathrm{C}\end{array}$ & $\begin{array}{c}\text { Max. Temp. } \\
\text { in BSP, }{ }^{\circ} \mathrm{C}\end{array}$ \\
Case 2 & 308.6 & $401.3 / 707$ & $599.2 / 1127.2$ & ${ }^{\mathrm{b} 580 / 1075.8}$ \\
Case 3 & 289.6 & $412.6 / 738$ & $600 / 1123.7$ & $221.1 / 428.6$ \\
Case 4 & 307.7 & $413 / 738.8$ & $600.4 / 1124.8$ & $271.1 / 466.8$ \\
Case 5 & 307.8 & $413 / 738.8$ & $600.4 / 1124.8$ & $271.1 / 467.4$ \\
Case 6 & 279 & $402 / 706.8$ & $600 / 1123.7$ & $289 / 522.5$ \\
Case 7 & 280 & $402 / 707$ & $600 / 1123.9$ & $289.3 / 498.7$ \\
d Case 8 & 280.8 & $401.2 / 707$ & $600 / 1123.9$ & $294.4 / 502.5$ \\
\hline
\end{tabular}

a"Equivalent backside temperature of BM and TDA.

${ }^{b}$ Max. Temperature of graphite rim (facing divertor chamber).

${ }^{\mathrm{c} C}$ Corresponding to the scenarios of $250 \mathrm{~kW} / \mathrm{m}^{2}$ and $500 \mathrm{~kW} / \mathrm{m}^{2}$.

${ }^{\mathrm{d}}$ At the end of transient thermal analysis.

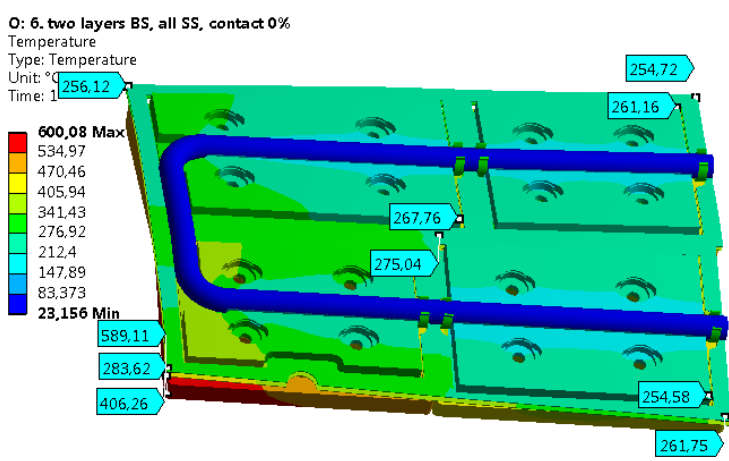

Fig. 3. Temperature distribution in BM tiles and BSP (Case 7: $250 \mathrm{~kW} / \mathrm{m}^{2}$ heat flux).

As indicated in Table III, without BSP (Case 1), the backside equivalent temperature could reach up to $470{ }^{\circ} \mathrm{C}$, which is lower than the above mentioned $\sim 600{ }^{\circ} \mathrm{C}$ due to the consideration of cooling pipe surfaces in FE calculation, and the hot spot temperature of graphite tile rim (facing divertor chamber) is very high and close to the maximum temperature of graphite tile facing plasma. The backside equivalent temperature and BSP hot spot temperature are reduced considerably by introducing the BSP, and further by second layer of the BSP. Moreover, if the BSP material is SS, the shielding effect could be additionally improved. The lowest backside equivalent temperature found by the study is $279{ }^{\circ} \mathrm{C}$. Thermal contact conductance between BSP and cooling pipes has marginal influences on shielding effect due to the thermal equilibrium is rapidly reached and dominated by the thermal radiation. The transient thermal analysis (Case 8) shows that the steady state could be reached in about 10 minutes, which means the steady state thermal analysis results represent well the BSP thermal behavior during the 30 minutes operation pulse.

\section{ELECTROMAGNETIC FORCES IN BSP}

The W7-X superconducting magnet system consists of 50 non-planar coils (NPC) and 20 planar coils (PC) that are toroidally arranged in five equal modules $\left(72^{\circ}\right.$ for each module), each one consisting of two symmetric semi-modules. Each semi-module comprises five differently shaped NPC and two different PC [7] to produce required magnetic inductance (B). During fault conditions of operation, a fast discharge of coil currents could be triggered by quench detection system (QD) to remove the stored energy from sc coils. As a result, considerable eddy currents (I) in the BSP is induced by the varying magnetic flux, as well as the Lorentz forces result from $\mathbf{I} \times \mathbf{B}$. Meanwhile, due to the BSP is close to plasma, a very fast plasma current decay could also induce considerable eddy currents in the BSP. There are two kinds of plasma currents, i.e. toroidal plasma current follows plasma axis and diamagnetic plasma current in poloidal direction. The parameters for the estimation of maximum EM forces in the BSP are:

1). sc coil current decay with time constant of 3 seconds, the magnetic field configuration 'low shear' (LS) with $3.0 \mathrm{~T}$ average field on plasma axis is selected [8], the currents in 7 types of sc coils are 18.2, 17.9, 16.9, 13.7, 13.5, -11.6 and 12.1 $\mathrm{kA}$ respectively,

2). Toroidal plasma current of $100 \mathrm{kA}$ with decay time constant of $1 \mathrm{~ms}$,

3). Diamagnetic plasma current of 2.2 MA (in total) with decay time constant of $1 \mathrm{~ms}$.

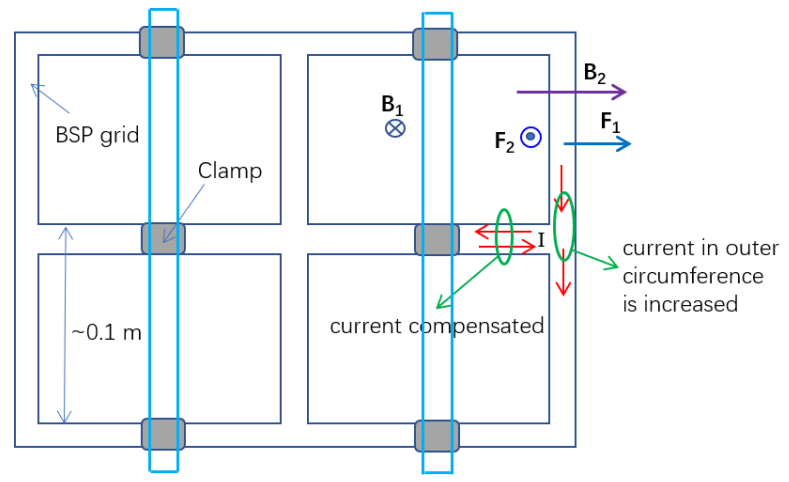

Fig. 4. Schematic view of the EM forces acting in BSP grids. 
A schematic view of EM forces in BSP is shown in Fig. 4. The induced eddy current is result from the varying magnetic inductance $\left(\mathbf{B}_{1}\right)$ perpendicular to the in-plane directions, and mainly focused on the outer edge of BSP grid due to the compensation effect of neighboring cells inside the grid (field differences are neglected). The in-plane force $\mathbf{F}_{\mathbf{1}}$ is a result from $\mathbf{I} \times \mathbf{B}_{1}$, and out-of-plane force $\mathbf{F}_{2}$ is a result from $\mathbf{I} \times \mathbf{B}_{2}$. In general, the induced eddy current could be described by the following formulas:

$\frac{d \varphi_{12}}{d t}=M_{12} \cdot \frac{d i_{1}}{d t}=u_{1}+u_{2}$

$u_{1}=L_{2} \cdot \frac{d i_{2}}{d t}, \quad u_{2}=R_{2} \cdot i_{2}$

$\tau_{2}=L_{2} / R_{2}$

$i_{2}$ - eddy current, $i_{1}$ - source current, $M_{12}$ - mutual inductance between $i_{1}$ and $i_{2}$ current loops, $R_{2}$ - resistance of eddy current loop, $L_{2}$ - self-inductance of eddy current loop, $\varphi_{12}$ - the magnetic flux passing through the eddy current loop, $\tau_{2}-$ time constant of eddy current loop.

According to rough estimation, the time constant of the $\operatorname{BSP}\left(\tau_{2}\right)$ is around $\sim 0.1 \mathrm{~ms}$, which is more than one order of magnitude lower than plasma current decay time constant $\left(\tau_{p}=1 \mathrm{~ms}\right)$ and much lower than sc current decay time constant $\left(\tau_{s}=3 \mathrm{~s}\right)$, therefore, $u_{1}$ is small and negligible comparing with $u_{2}$, and the equation (2) could be rewritten as:

$\frac{d \varphi_{12}}{d t}=R_{2} \cdot i_{2}$

TABLE IV

MAXIMUM EM FORCES IN BSP (0.5/0.1 MM OF SS/CU)

\begin{tabular}{ccccccc}
\hline \hline \multirow{2}{*}{$\begin{array}{c}\text { Grid } \\
\text { size }\end{array}$} & \multicolumn{2}{c}{ sc currents decay } & \multicolumn{3}{c}{ Toroidal plasma } \\
current decay & \multicolumn{3}{c}{ Diamagnetic plasma } \\
current decay \\
& ${ }^{\mathrm{a}} \mathrm{F}_{1}, \mathrm{~N}$ & ${ }^{\mathrm{b}} \mathrm{F}_{2}, \mathrm{~N}$ & $\mathrm{~F}_{1}, \mathrm{~N}$ & $\mathrm{~F}_{2}, \mathrm{~N}$ & $\mathrm{~F}_{1}, \mathrm{~N}$ & $\mathrm{~F}_{2}, \mathrm{~N}$ \\
$1 \times 1$ & 0.56 & 0.27 & 5.20 & 16.46 & 1.15 & 1.72 \\
$2 \times 2$ & 1.12 & 0.54 & 10.40 & $\mathbf{3 2 . 9 2}$ & 2.30 & 3.44 \\
$2 \times 3$ & 1.35 & 0.65 & 12.48 & 39.50 & 2.76 & 4.13 \\
$3 \times 3$ & 1.68 & 0.81 & 15.60 & 49.37 & 3.45 & 5.15 \\
$4 \times 4$ & 2.25 & 1.09 & 20.79 & 65.83 & 4.59 & 6.87 \\
$5 \times 5$ & 2.81 & 1.36 & 26.0 & 82.29 & 5.74 & 8.59 \\
$6 \times 6$ & 3.37 & 1.63 & 31.19 & 98.75 & 6.89 & 10.31 \\
\hline
\end{tabular}

${ }^{\mathrm{a}}$ In-plane forces, considering an edge length of $0.1 \mathrm{~m}$ (see Fig. 4).

${ }^{\mathrm{b}}$ Out-of-plane forces.

The maximum magnetic field (parallel and perpendicular to the in-plane directions) in the BSP from sc and plasma current is calculated at first, and the maximum possible eddy current is estimated according to equation (5). And then the maximum EM forces are estimated using $\mathbf{I} \times \mathbf{B}$. The estimation is done for the BSP grid with $0.5 / 0.1 \mathrm{~mm}$ of SS/Cu in order to mitigate EM forces. A thin layer of $\mathrm{Cu}$ (facing divertor chamber) is necessary to be implemented in order to reduce the ECRH absorption on the BSP surface. Table IV lists the estimation results of maximum EM forces (for the grid edge length of 0.1 $\mathrm{m})$ in BSP with the dependence on the number of cells in the grid. Larger grid makes the manufacture and installation process easy but increases the EM forces in the BSP drastically. Therefore, a compromised grid size necessary to be defined according to mechanical assessment.

\section{MeChaniCAl ANALYSIS OF BSP FIXATION}

The BSP grid is fixed on the cooling pipes by clamps, which are formed from composite material $\mathrm{SS} / \mathrm{Cu}$ with thickness of $0.9 / 0.1 \mathrm{~mm}$ (see Fig. 1).

Concerning the thermo-mechanical stability of the BSP fixation the following statements are valid:

1). The BSP could be easily expanded under temperature gradient due to their flexible attachment pattern, which lead to low and acceptable thermal stresses in the BSP,

2). The in-plane EM forces (10.4 N in maximum for the grid size of $2 \times 2$ ) could be taken by in-plane tension / compression of the BSP,

3). The bending moments due to the EM forces perpendicular to the BSP plane may be detrimental and are of most concern.

According to the EM forces listed in Table IV and the explanation of the bending moment calculation in Fig. 5, the maximum bending moment on single clamp is expected as 1.65 $\mathrm{N} \cdot \mathrm{m}(32.9 \mathrm{~N} \times 0.05 \mathrm{~m})$ for a grid size of $2 \times 2$, The value is significant for such flexible structure. Moreover, the transient effect with time scale of $\sim 1$ ms needs to be considered. The transient mechanical analysis is performed with a half model of the clamp under the force of $16.5 \mathrm{~N}$ in downward direction (see Fig. 6). The deformation in opposite direction is constrained by the graphite tiles (see Fig. 1, the distance between BSP and graphite tile is $\sim 2.5 \mathrm{~mm}$ ), therefore it is less critical for the structure. Fig. 6 shows the model, the boundary conditions and the assumed force evolution for transient mechanical analysis. The friction factor between clamp and pipe is set to $10 \%$. The damping ratio ( $\xi$, Rayleigh Damping) is assumed as a constant of $4 \%$ [9], from which and the main natural frequencies (from modal analysis) the mass coefficient $(\alpha)$ and the stiffness coefficient $(\beta)$ are calculated according to:

$\xi=\frac{\alpha}{2 \omega_{i}}+\frac{\beta \omega_{i}}{2}$

$\omega_{i}$ is the circular frequency of the mode $i$. Due to the lowest $\omega_{i}$ of about $1250(\mathrm{rad} / \mathrm{s})$, the contribution from mass damping could be neglected, and the stiffness coefficient of $6.366 \times 10^{-5}$ is taken for the transient mechanical analysis. In addition, the elastic modulus and material hardening of BSP (SS/Cu with thickness of $0.5 / 0.1 \mathrm{~mm}$ ) for transient mechanical analysis are listed in Table $\mathrm{V}$, the smeared material properties are calculated according to the material properties of $\mathrm{Cu}$ and SS in $[6,10]$.

TABLE V

Elastic Modulus AND Material HaRdening OF SS/Cu (0.5/0.1 MM)

\begin{tabular}{cccccc}
\hline \hline $\begin{array}{c}\text { Temp. }{ }^{\circ} \mathrm{C} \\
\text { Elastic modulus } \\
(\mathrm{GPa})\end{array}$ & 183.5 & 1700 & 200 & 300 & 400 \\
\hline Plastic strain & 0.0 & 0.0101 & 171.7 & 164 & 163.2 \\
Stress (MPa) & 276 & 283 & \multicolumn{2}{c}{0.384} \\
\hline \hline
\end{tabular}




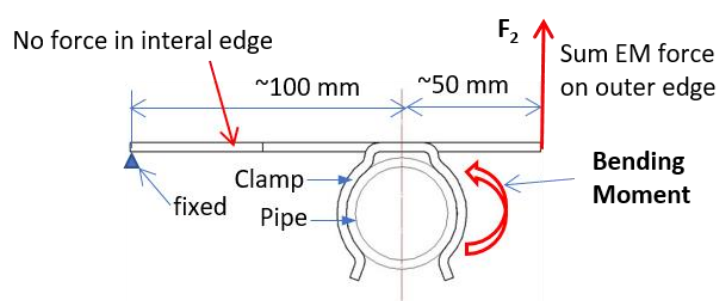

Fig. 5. Explanation of bending moment estimation for single BSP clamp.

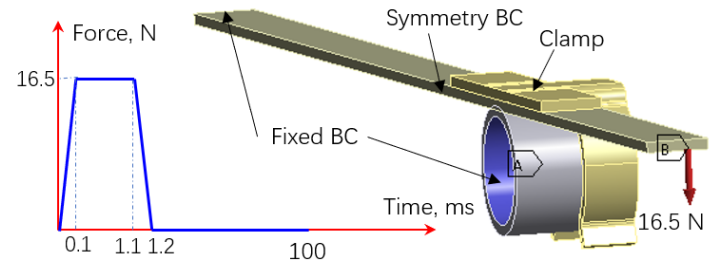

Fig. 6. Assumed force evolution for transient mechanical analysis (left) and FE model of half BSP fixation (right).

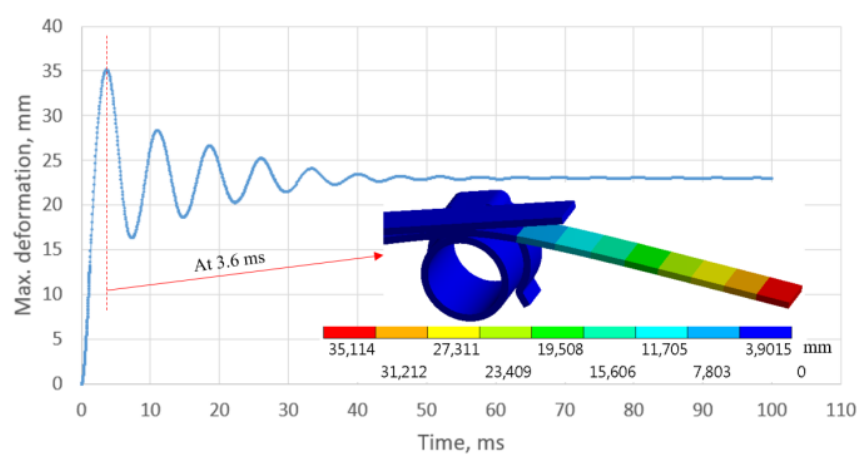

Fig. 7. Evolution of the maximum deformation and displacement distribution (at the time with maximum deformation).

Fig. 7 shows the evolution of maximum deformation over the time and the displacement distribution at the time with maximum deformation. As indicated, the residual deformation is about $23 \mathrm{~mm}$ which is result from the plastic strain of up to 7 $\%$ in the BSP. Due to the maximum plastic strain is far below the elongation of stainless steel $(\sim 40 \%)$, there is no danger of a break of BSP edges during such extreme event of toroidal plasma current decay. A detachment of the clamp is not foreseen also due to restrictions on both sides either by cooling pipe or by graphite tile (see Fig. 1). However, the BSP thermal shielding effect could be affected due to the loss of shielding area and/or touching other hot components. Fortunately, events of sc coil and diamagnetic plasma currents decays are completely safe due to much smaller EM forces ( 10 times lower, see $F_{2}$ in Table IV). Finally, the double-layered BSP design option with maximum grid size of $2 \times 2$ (or $2 \times 3$ for some region with lower magnetic field), made from the material of $0.5 / 0.1 \mathrm{~mm}$ thickness $\mathrm{SS} / \mathrm{Cu}$, is approved by the project with the following argumentations:

1). The event of toroidal plasma current decay from $100 \mathrm{kA}$ with time constant of $1 \mathrm{~ms}$ is an extreme fault case which is rarely or even never happens during operation.

$2)$. In case some BSPs are out of function, a replacement process could be conducted relatively easy (fully accessible if the graphite tiles are dismounted).
3). The eddy current in the BSP could be further reduced in newly installed by introducing some cuts on $\mathrm{Cu}$ layer if the budget of BSP production is allowed.

Fig. 8 shows the designed double-layer BSP with some bended tips to ensure the BSP grids and graphite tile rims are untouched at the corner.

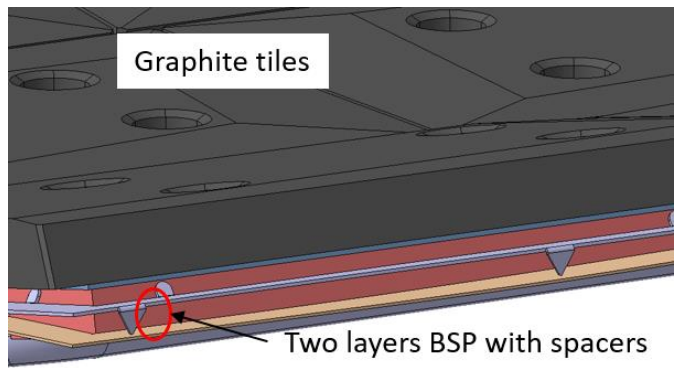

Fig. 8. Two layers BSP with some spacers.

\section{APPROACHES TO Minimize THE COST}

Due to various position and orientation of the baffle modules in the divertor room (formed by PV, BM, HHF divertor and divertor closures), some of them introduce less heat radiation on the CVP and could be excluded from the installation of BSP in order to minimize the overall cost. Therefore, a few thermal analysis iterations for the CVP are repeated to identify the baffle modules which introduce less radiant heat on the CVP [4]. The current LN2 cooling capacity for one CVP in module 1 or 5 is about $1.9 \mathrm{~kW}$ [11], which is the upper bound for optimizing the number of BSPs to be installed.

The optimization result is shown in Fig. 9, there are four baffle modules and toroidal closure (for all CVPs in different divertor rooms) are necessary to be equipped with the BSP to have the LN2 heat load of single CVP of $\sim 1.95 \mathrm{~kW}$ (in module 1 or 5), and a total heat load on all ten CVPs is around $13.1 \mathrm{~kW}$ (lower heat loads for the CVPs in other modules [4]), which are still manageable with the present LN2 cooling system capacity dedicated for CVPs.

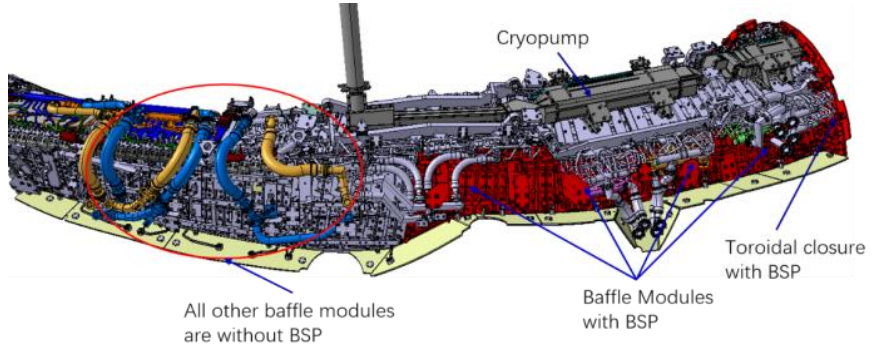

Fig. 9. Baffle modules to be installed with BSP: Result of optimization process.

In addition, some other in-vessel components beneath the $\mathrm{BM}$, such as $\mathrm{SS} / \mathrm{Cu}$ tubes and diagnostics, suffer also from the high thermal radiation from BM backside surface, and in some cases the hot spot backside temperature facing such sensitive components is to be limited. The developed BSP for the CVP is also suitable for these components, therefore, the installation of BSP for other baffle and heat shield modules [3] is also recommended and depends on the specific requirement of the components beneath them. 


\section{CONCLUSIONS}

Due to the expected high plasma radiation on the first wall of plasma facing components during the steady state operation of W7-X, the installation of backside protection is strongly required to reflect the thermal radiation from the hot graphite tiles rim in order to mitigate the heat load on the CVP LN2 cooling circuit and other sensitive components.

The shielding effects of BSP are studied in detail with respect to the number of BSP layers, material of BSP grid and thermal contact conductance, and the results indicate that the BSP with double-layered SS grids has the best shielding effect. The maximum BSP grid size is defined according to the result of transient mechanical analysis of BSP under maximum EM forces. Finally, the BSP structural stability and possible consequences during fast decay of sc and plasma currents are discussed. According to the analysis results and presented considerations, the double-layered BSP approach with maximum grid size of $2 \times 2$ (or $2 \times 3$ for some region with lower magnetic field), and with the material SS/Cu (thickness $0.5 / 0.1 \mathrm{~mm})$, is approved and under implementation in the project.

Moreover, the repeated thermal analysis of the CVP taking into account the available LN2 cooling capacity indicates that some BM could be excluded from the process of the BSP installation in order to minimize the costs. On the other hand, the developed design of BSP is also suitable to protect other sensitive components behind baffle and heat shield modules.

\section{ACKNOWLEDGMENT}

This work has been carried out within the framework of the EUROfusion Consortium and has received funding from the Euratom research and training programme 2014-2018 and 2019-2020 under grant agreement No 633053. The views and opinions expressed herein do not necessarily reflect those of the European Commission.

\section{REFERENCES}

[1] H. S. Bosch et al., "Engineering Challenges in W7-X: Lessons Learned and Status for the Second Operation Phase," IEEE Trans. Plasma Sci., vol. 46, no. 5, pp. 1131-1140, 2018.

[2] A. Peacock, J. Boscary, et al., "Status of High Heat Flux Components at W7-X," IEEE Trans. Plasma Sci., vol. 42, no. 3, pp. 524-532, 2014.

[3] R. Stadler, A. Vorköper, J. Boscary, et al., "The in-vessel components of the experiment WENDELSTEIN 7-X," Fusion Eng. Des., vol. 84, pp. 305-308, 2009.

[4] J. Zhu, V. Bykov, et al., "Refined Multiphysics Analysis of W7-X Cryopumps," IEEE Trans. Plasma Sci., vol. 46, no. 5, pp. 1592-1602, 2018.

[5] ITER Material Properties Handbook, ITER, Cadarache, France.

[6] Superconducting Material Database (DRG1 Annex, Article 5), ITER, Cadarache, France.

[7] T. Rummel, K. Riße, et al., "The Superconducting Magnet System of the Stellarator Wendelstein 7-X," IEEE Trans. Plasma Sci., vol. 40, pp. 769-776, 2012.

[8] V. Bykov, J. Zhu, A. Carls, et al., "Engineering Challenges of W7-X: Improvement of Numerical Modeling and Mechanical Monitoring after Commissioning and First Phase of Operation," Fusion Science and Technology, vol. 72, pp. 546-558, 2017.
[9] Ki-Hyoung Kee, et al., "Integrity Analysis of an Upper Guide Structure Flange,” Nucl. Eng. Technology, vol. 47, pp. 766-775, 2005. [10] Joris Fellinger, "Plastic limit analysis of LSE DO6 Mono-block design in EN 1.4429", W7-X project document, PLM: 1-GXA10M-T0013.0.

[11] M. Nagel, M. Ihrke, et al., "Concept for the Cryo Distribution for the Wendelstein 7-X Cryo Vacuum Pumps," IOP Conf. Series: Materials Science and Engineering, vol. 502, p. 012109, 2019. 